\title{
PET-Saúde:
}

\section{uma experiência potencialmente transformadora no ensino de graduação}

Marize Melo dos Santos ${ }^{(a)}$

Otacílio Batista de Sousa Nétto ${ }^{(b)}$ José Ivo dos Santos Pedrosa ${ }^{(c)}$

Lúcia da Silva Vilarinho(d)

\section{Introdução}

O processo de formação de profissionais na modernidade toma, como referência, o processo de trabalho determinado e organizado sob os princípios do modo de produção capitalista: produtividade e competitividade. No campo da saúde, essa direcionalidade da formação tem suscitado discussões a respeito de sua adequação à organização do processo de trabalho na saúde tal como preconizado pelos moldes tayloristas, assim como discussões que compreendem a intrínseca articulação entre a formação e o processo de trabalho. Este último funciona como elemento significante para a formação, originando concepções, como: aprendizagem significativa, integração ensino-serviço-comunidade e educação permanente em saúde 1 .

No Brasil, tais questões adquirem maior visibilidade na Política Nacional de Educação Permanente em Saúde, que advoga intervenções para uma formação articulada com o Sistema Único de Saúde (SUS), tendo as redes de serviços de saúde como cenário de aprendizagem e as competências a serem desenvolvidas como característica do perfil profissional a ser formado².

Tal política, lançada em 2004 e atualizada desde então por meio de portarias ministeriais, afirma o papel do Ministério da Saúde como ordenador da formação profissional em saúde, e apresenta, em sua implantação, estratégias que compreendem a promoção de ações voltadas para a aproximação da formação com os serviços públicos. Um exemplo é o Programa de Educação pelo Trabalho em Saúde (PET-Saúde), que preconiza o processo ensino-aprendizagem na rede de serviços, envolvendo docentes, estudantes, equipes de saúde dos serviços e usuários do SUS ${ }^{3}$.

Para operacionalizar tais estratégias, o Ministério da Saúde, em parceria com o Ministério da Educação, lança editais convocando as Instituições de Ensino Superior (IES) a apresentarem propostas para o desenvolvimento de ações de formação nos cenários das redes de serviço do SUS ${ }^{4}$.

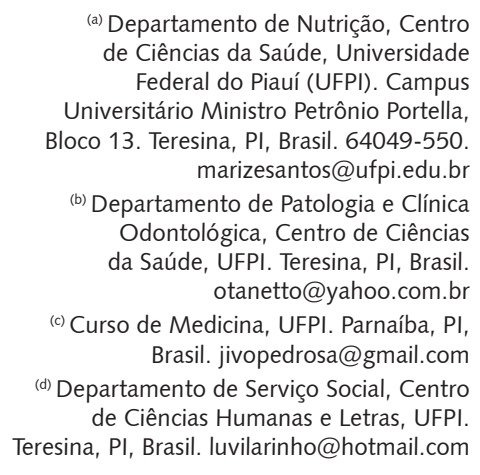

(a) Departamento de Nutrição, Centro de Ciências da Saúde, Universidade Federal do Piauí (UFPI). Campus Universitário Ministro Petrônio Portella, Bloco 13. Teresina, PI, Brasil.64049-550. marizesantos@ufpi.edu.br

(b) Departamento de Patologia e Clínica Odontológica, Centro de Ciências da Saúde, UFPI. Teresina, PI, Brasil. otanetto@yahoo.com.br (c) Curso de Medicina, UFPI. Parnaíba, PI, Brasil.jivopedrosa@gmail.com (d) Departamento de Serviço Social, Centro de Ciências Humanas e Letras, UFPI. Teresina, PI, Brasil. luvilarinho@hotmail.com 


\section{O percurso para a concretização do sonho}

O nosso ponto de partida na travessia deste sertão chamado Programa Nacional de Reorientação da Formação Profissional em Saúde (Pró-Saúde) articulado ao Programa de Educação pelo Trabalho para a Saúde (PET-Saúde) começa com a publicação do Edital 24, de 15 de dezembro de 2011, do Ministério da Saúde, por intermédio da Secretaria de Gestão do Trabalho e da Educação na Saúde (SGTES), convocando para a seleção de projetos de Instituições de Ensino Superior no período de 16/12/2011 a 15/03/20125.

Consideramos sertão mais do que uma região com específicas características físicas e climáticas; significa também um universo, um modo de viver e ser pouco (re)conhecido por outros modos de viver, além de ser repleto de desafios e possibilidades de superação $0^{6,7}$.

A UFPI já possuía tradição no Pró-Saúde, tendo em vista a participação do curso de odontologia na chamada pública desse projeto em 2005. Com uma proposta aprovada, conseguiu implementar uma série de mudanças: na integração dos seus estágios curriculares extramuros com as unidades de saúde da família do município de Teresina, na educação permanente dos profissionais da rede municipal de saúde bucal de nível Superior e Médio, na aquisição de insumos e equipamentos destinados a essa rede e, também, em equipamentos voltados para as próprias clínicas intramuros ${ }^{8}$.

Por não conseguir viabilizar a participação do curso de medicina nas edições posteriores do PETSaúde, a UFPI abdicou de novas propostas, o que mudaria, apenas, com o advento do edital conjunto Pró-PET Saúde de 2011/2012. Se antes havia a proposta isolada e corajosa de um curso, desta vez, haveria um coletivo de professores de diferentes cursos da grande área da saúde, abrigados em um espaço colaborativo, compartilhado e protegido para propostas como a que se descortinava no edital, o Núcleo de Estudos em Saúde Pública (NESP), da UFPI.

O NESP, desde a sua fundação, foi uma espécie de incubadora de projetos e atividades, de relações institucionais com as secretarias, estadual e municipal, de saúde, mas que precisava ser redescoberto/ renascido em suas potencialidades criadoras e transformadoras, especialmente: no tocante à educação interprofissional no campo da saúde coletiva, na partilha de dispositivos e de experiências de integração ensino-serviço-comunidade e, por fim, na temática do ensino na saúde, onde já havia uma iniciativa promissora com um projeto financiado pela CAPES, de mesmo nome, capitaneado pelo Prof. Dr. José Ivo dos Santos Pedrosa, também gerente do Núcleo9.

De dezembro de 2011 a março de 2012, o NESP viu, nas suas salas, um intenso movimento: de professores dos cursos de educação física, enfermagem, medicina, nutrição, odontologia e serviço social; de potenciais preceptores (profissionais dos serviços públicos de saúde contactados para conhecerem e se inserirem na proposta); e de alunos dos cursos envolvidos, que se entusiasmaram frente à possibilidade de bolsa remunerada, claro, mas, também, de uma outra forma de ensinar e aprender em saúde, em diferentes cenários de práticas com outros atores que não os seus convencionais professores.

Para felicidade de todos, o esforço não foi em vão; a proposta da UFPI foi aprovada, sendo contemplados dois projetos, os quais foram tutorados por professoras do Curso de Nutrição, com o PET-Promoção de Saúde, e do Curso de Serviço Social, com o PET-Saúde/Redes de Atenção à Saúde, com a participação dos profissionais de saúde de duas das três coordenações regionais de saúde da Fundação Municipal de Saúde (Leste/Sudeste e Sul). Manteve-se a proporção dos alunos bolsistas dos seis cursos originalmente envolvidos, selecionados mediante um rito simplificado que envolveu o índice de rendimento acadêmico e uma carta de intenções para participar do programa e sobre a sua particular visão do Sistema Único de Saúde. Ao final da seleção, 24 alunos foram selecionados.

Por fim, o Pró-PET-Saúde, idealizado por grupos de professores dos diversos cursos da área de saúde e de Serviço Social, foi posto em prática, iniciando em meados de setembro de 2012. E o verdadeiro grande sertão agora se revelaria nas suas veredas. 


\section{Estratégias metodológicas}

As políticas públicas voltadas para a promoção da saúde fortalecem-se na perspectiva de desenvolverem estratégias para o monitoramento e avaliação da situação de saúde da população nas diferentes fases da vida.

Considerando que a educação promove a aquisição (problematização e empoderamento) de novos conhecimentos e pode imprimir, no indivíduo, mudanças de hábitos (aquisição de atitudes e competências) favoráveis à sua autonomia, o PET-Promoção da Saúde foi uma proposta ousada, na qual se vislumbrava a articulação entre: os estudantes dos cursos de Odontologia, Nutrição e Educação Física, da Universidade Federal do Piauí, preceptores dos Serviços de Saúde da Fundação Municipal de Saúde (nutricionistas, odontólogos e educadores físicos da rede municipal de serviços de saúde) e comunidades adstritas a esses serviços, acompanhadas nos cenários eleitos para esse desafio, na perspectiva do desenvolvimento de processos educativos autonomizadores.

Assim, pretendeu-se contribuir com a consolidação da política de formação em saúde tendo como pano de fundo o Sistema Único de Saúde em sua complexidade e amplitude, a partir da realização de oficinas para a promoção de estilos de vida saudáveis, incluindo temas sobre qualidade de vida que envolvessem, em um sentido amplo, nunca restrito, a nutrição, a odontologia e as atividades físicas. Esse desafio fomentou uma nova formação/ação dos profissionais e estudantes, enfatizando novas estratégias, transformando os cenários de atenção básica, os territórios e/ou redes de promoção da saúde, em locais prioritários (estratégicos) de formação e de nossas intervenções.

A proposta deste relato é descrever as experiências vividas e contadas pelos atores dos cenários do Pet-Promoção da Saúde no referido período de atuação. Essas experiências desencadearam-se a partir de quatro questões norteadoras:

a) Qual a sua relação com os alunos de outros cursos?

b) Como o PET-Saúde contribuirá para a sua vida profissional?

c) Como o PET-Saúde contribui na sua formação e transformação?

d) Qual foi a experiência que o(a) marcou durante o projeto?

Também são relatadas as experiências vivenciadas em três cenários utilizando-se a estratégia da Tenda do Conto (TC). A TC constitui um espaço aconchegante para receber pessoas que contam suas histórias de forma leve e descontraída. É uma estratégica dinâmica que oferece a escuta protegida para o outro, como um círculo de aprendizagem e respeito, com possibilidade de discussão, em momento posterior, pelos profissionais e equipes de saúde, vislumbrando a discussão e resolução de problemas identificados em seus diversos âmbitos.

Como conta Jacqueline Abrantes Gadelha ${ }^{10}$, enfermeira, da cidade de Natal/RN, que iniciou o trabalho com a Tenda do Conto:

"a TC parece resumir o que sentimos: surpreende-nos sempre, impossível prever o que vai acontecer no decorrer de cada encontro. A construção é ali e agora, puro trabalho vivo em ato. Cada história traz o poder de nos religar ao universo da alma humana. Muitas delas não sairão mais das nossas memórias".

Essas sensações são contadas pelos estudantes e preceptores que vivenciaram as histórias nos cenários.

\section{Experiências no cotidiano do PET-Promoção da saúde, descritas pelos estudantes}

$1{ }^{\text {a }}$ Questão: Qual a sua relação com os alunos de outros cursos?

"Relacionar-se com alunos de outros cursos foi ter uma visão mais ampla de promoção da saúde para o ser humano. O PET me proporcionou a oportunidade de olhar para horizontes mais distantes e almejar alcançá-los. A interação com estudantes de outros cursos traz novos conhecimentos, enriquece-nos. Sou estudante de nutrição e relacionei-me com estudantes 
da odontologia e educação física. Essa experiência me fez entender que interdisciplinaridade na saúde é conhecer mais o ser humano e ajudá-lo com mais propriedade, intimidade e humanidade". (Acadêmica de Nutrição, MFP)

"A parte mais difícil, inicialmente, no programa foi sem dúvida o relacionamento com alunos de outras áreas, pois isso tudo é muito novo, até um tanto desesperador, mas com o passar do tempo vamos percebendo que juntos podemos ir bem mais longe e sem dúvida a parte mais interessante das atividades foi essa convivência com os estudantes e profissionais das mais diversas áreas. O conhecimento é multiplicado, o trabalho é dividido e somamos as potencialidades de sucesso". (Acadêmico de Educação Física, ELBA)

"A experiência se revela muito boa e dinâmica, pois somos beneficiados em conhecer os demais colegas que estudam em blocos da universidade que são próximos, mas que, ao mesmo tempo, se tornam longe pela carga horária, atividades e a própria universidade que não se dá conta dessa integração ensino-ensino. A troca de informações, planejamento de atividades conjuntas e a amizade que o PET nos proporciona com os alunos dos demais cursos são grandes legados e privilégios que só os participantes têm". (Acadêmico de Odontologia, JHRS)

\section{$2^{a}$ Questão: Como o PET-SAÚDE contribuirá para a sua vida profissional?}

"Aprendi, acima de tudo, que o planejamento bem feito e envolvendo muitas áreas do conhecimento, pode contribuir para um bom resultado das ações desenvolvidas e a partir daí ajudar da melhor forma no atendimento a quem mais precisa". (Acadêmico de Odontologia, MACLN)

"Abriu meus olhos para outros ambientes de trabalho além de academias e colégios". (Acadêmica de Educação Física, TSA)

“Foi uma experiência que trouxe mudanças na minha forma de enxergar o mundo, reconhecer a realidade, identificar as necessidades. Experiência muito rica e que vai muito além de coisas objetivas. É a sensibilidade ao olhar para o outro. Isso é algo que vou levar para minha vida profissional". (Acadêmica de odontologia, NAC)

\section{$3^{a}$ Questão: Como o PET-SAÚDE contribui na sua formação e transformação?}

“Temos uma formação ainda muito fechada e um pouco distante da realidade social. O PET é uma oportunidade para conhecer os serviços de saúde e aprender com quem trabalha neles, com incentivo ao pensar e ao agir diante do que identificamos e conhecemos, da troca de experiências, do trabalho integrado e do diálogo". (Acadêmica de odontologia, NAC)

“O PET amplia o campo de visão do aluno. Faz com que ele supere barreiras que jamais pensaria em ultrapassar, de sentir na pele como é dura a rotina do serviço. O contato direto com a sociedade faz com que o aluno fique mais "humano" e sensibilizado com a realidade da sociedade, consequentemente, o torna mais decidido e engajado nos seus objetivos como futuro profissional". (Acadêmico de Nutrição, PVLS)

"Percebemos quando falamos aos colegas, não petianos, que será realizada uma roda de conversa ou uma oficina sobre a vida com usuários/pacientes de determinado local. A reação é quase sempre "vocês vão pra lá só pra conversar"?" ou "qual é exatamente a função de vocês?" e, ainda, "O que é PET?". Talvez esses alunos não tenham bem em mente que o ser humano, antes de medicação, precisa de atenção; que remédios, por si só, não curam quem está deprimido; que antes de se falar em escovação é preciso perguntar se o paciente 
tem escova, creme dental em casa... realidades que são bem vividas no PET, já que estamos diretamente com usuários/pacientes/realidades/necessidades. O PET desperta para o lado humanizado e acolhedor como futuro profissional". (Acadêmico de Odontologia, JHRS)

$4^{a}$ Questão: Qual foi a experiência que o(a) marcou durante o projeto?

"Várias experiências foram marcantes, porém uma delas foi a chacina que ocorreu numa zona rural de Teresina-Pi, quando estava atuando juntamente com a equipe do NASF. Fomos visitar a família eu, a educadora física e a psicóloga. Foi uma conversa difícil mas emocionante... Foi um momento de solidariedade, fé, força, apoio, onde tivemos que demonstrar a família para que eles sentisse segurança que precisavam seguir em frente mas que podiam continuar com o luto. E sensibilizar o chefe da família a não tomar decisões precipitadas uma vez que ainda estava muito cedo e os sentimentos ainda estavam misturados e aflorados". (Acadêmica de Nutrição, IFS)

"A experiência mais marcante foi vivenciado no CAPS II Sudeste, estávamos participando das atividades físicas, e uma usuária que nunca havia participado do grupo ao ver todos nós, alegres durante a prática aproximou-se, timidamente, de mim e a convidei para participar das atividades, e juntos realizamos os exercícios, percebi que aquela pessoa tímida e que sempre ficava no seu canto estava pela primeira vez com um sorriso estampado no rosto, este sorriso no rosto foi sem duvida o momento mais marcante que vivenciei nas atividades desenvolvidas no PET". (Acadêmico de Educação Física, ELBA)

\section{Experiências na Tenda do Conto}

\section{Unidade Básica de Saúde/Núcleo de Apoio à Saúde da Família}

Essa experiência foi realizada no dia 5 de agosto de 2014. A Tenda recebeu: os participantes do Programa HIPERDIA, outras pessoas convidadas, alunos da disciplina Educação Nutricional, alunos do PET: Promoção da Saúde, alunos da Residência Multiprofissional em Saúde da Família, da Universidade Estadual do Piauí (UESPI) e profissionais do serviço.

Segundo os alunos:

"a tenda do conto traz uma proposta de gerar novas relações. Ao ser apresentada a turma esta estratégia para se trabalhar educação nutricional, nos agradou pelo estilo informal, porém quando nos foi feita a proposta, surgiu o medo do novo, de sair do comodismo e ousar fazer algo diferente do que estávamos habituados. Superamos, e então foi realizada a primeira tenda em sala de aula. Um encontro regado de boas histórias, onde nós, colegas, nos conhecemos ainda mais. Saímos da aula empolgados para fazermos o mesmo, agora fora dos muros da universidade".

"A sala enfeitada com balões e papéis recortadas, as cadeiras em círculo, na mesa alguns objetos trazidos para serem utilizados para contar as histórias, em outra mesa frutas, e no meio a cadeira, onde o convidado contaria sua história, todo este cuidado para que se sentissem bem acolhidos".

"Os olhares estranhos para saber o que ali ocorreria, e nós, ansiosos para que fosse uma manhã prazerosa, o que no final aconteceu. Após a acolhida, foi lançado o convite para sentar-se na cadeira localizada no centro da sala e contar sua história sobre como convive com a doença, como se cuida, ou sobre qualquer assunto, se sentindo a vontade para contar, sem pressionar". 


\section{No CAPS III, Zona Sul de Teresina}

A Tenda do Conto no Centro de Atenção Psicossocial CAPS III foi realizada no dia 5 de agosto de 2014, com a utilização de painel fotográfico, com o objetivo de os pacientes escolherem uma ou mais fotos relacionadas a algo de suas vidas. Em seguida, eles explicavam o motivo da escolha das fotos; por fim, os mesmos eram convidados a confeccionar um desenho que representasse algum momento de suas vidas e, depois, eles explicavam o motivo da confecção do desenho.

Segundo o depoimento da preceptora:

\footnotetext{
“Várias histórias proporcionaram risadas, bem-estar... outras um pouco tristes, porém contadas como superação... O mais importante de tudo foi a integração, a participação de todos, tanto dos pacientes como dos profissionais, até mesmo aqueles mais resistentes aos grupos soltaram a voz na tenda do conto!!!! Hoje ficamos muito felizes... porque um paciente que nunca participou de nada, nunca falou nada, fez questão de contar um pouco de sua história! Gratificante!!! E, em muitas histórias, nós profissionais, descobrimos coisas que não sabíamos!!!! Coisas que não identificamos nas triagens!!! E, com isso, uma possibilidade de mudanças no curso do tratamento na Unidade!!!!!".
}

Inicialmente, apresentou-se a Tenda do Conto e sua finalidade. A aluna convidada a dar seu relato explicou a função dos alimentos e utensílios de cozinha que estavam na mesa; em seguida, contou uma "estória" vivida relacionada àquele utensílio, então, convidou os pacientes para também compartilharem suas "estórias".

De início, os participantes ficaram um pouco receosos de relatarem suas histórias na frente de todos, mas, aos poucos, eles foram se sentindo à vontade, embora tenham demorado um pouco para entender o objetivo da prática e até fugirem um pouco do assunto relatando fatos da sua vida pessoal e o motivo pelo qual frequentam o CAPS.

Foi uma experiência diferente na atenção ao paciente, visto que foi possível dar orientações de forma que os participantes ficassem à vontade para perguntar. Foi rompida a barreira do formal, tornando o diálogo mais confortável e dinâmico. A Tenda do Conto, como ferramenta educativa, é um método bem eficiente e que gera um feedback positivo.

\section{Impressões acerca do trabalho realizado}

Possibilitar encontros é a primeira e a mais forte impressão sobre os efeitos da experiência do PET-Saúde. São encontros entre alunos de cursos diferenciados, permitindo que se compreenda a concepção de campo e núcleo de prática (campos) tendo a Atenção Básica como referência; encontros entre docentes e profissionais, que passam a superar mitos que persistem sobre a relação universidade/ serviço/comunidade e a construir uma concepção dos serviços como espaços de produção de saberes e tecnologias; e encontros entre o mundo da vida, que passa a exigir respostas objetivas para os problemas do cotidiano.

Outro efeito altamente significativo é a produção de afetos que podem ser expressos nas falas, nos gestos e no sentir.

A aproximação com os serviços e com o cotidiano da população passa a ser elemento desconstrutor da cultura do profissional neutro, individualista e competitivo, abrindo caminhos para a formação de profissionais comprometidos ética e socialmente com: a democratização do acesso, atendimento humanizado, interdisciplinaridade, integração das instituições de saúde com a realidade, acesso democrático às informações, e estímulo à participação cidadã.

Além da dimensão mais subjetiva de cada ator/sujeito participante, os efeitos da Tenda do Conto revelam a potência de uma estratégia que "produz" possibilidades de autonomia para os envolvidos, na medida em que os coloca em situação de diálogo com outros sujeitos, recriando o que parecia natural e construindo sua posição como protagonista na história ${ }^{11}$. 
Finalizando, para além da metodologia utilizada, das boas intenções humanizadoras e humanizantes, dos desafios impostos pela queda dos muros do Campus Universitário, em Teresina, que cercam as fronteiras do ensino de saúde da UFPI, o potencial transformador e transformante que chama a atenção para a experiência PET é, sobretudo, este não saber o que fazer principal; é esta permanente busca pelo novo saber, traduzida em um novo arriscar-se a fazer; esta mudança observada nos relatos de todos os envolvidos, alguns mais disponíveis para a mudança e outros mais reticentes para o fluxo que a mudança traz no seu cerne de desterritorializaçäo.

Ao sair dos territórios estriados do mundo do saber acadêmico e navegar imprecisamente nos territórios nômades e lisos da vida e das necessidades de saúde que ela traz consigo, reconhecemos o PET como um dispositivo potente para alicerçar e alavancar mudanças de rumo, novas navegações de cabotagem, novas cartografias do cuidado em saúde. O alcance é limitado ao pequeno número de bolsistas e voluntários, e esta é uma crítica que precisamos fazer, mas, sem dúvida, o PET traz um fôlego renovado para os que dele participam, no sentido de refletirem sobre o passado, o presente e o futuro dos novos itinerários do saber e do fazer saúde, tendo sempre o SUS como campo liso e estriado.

\section{Colaboradores}

Os autores trabalharam juntos em todas as etapas de produção do manuscrito.

\section{Referências}

1. Frenk J, Chen L, Bhutta ZA, Cohen J, Crisp N, Evans T, et al. Profesionales de la salud para el nuevo siglo: transformando lá educación para fortalecer los sistemas de salud en un mundo interdependiente. Rev Peru Med Exp Salud Publica. 2011;28(2):337-41.

2. Ministério da Saúde (BR). Portaria n 198, de 13 de fevereiro de 2004. Institui a Política Nacional de Educação Permanente em Saúde como estratégia do Sistema Único de Saúde para a formação e o desenvolvimento de trabalhadores para o setor e dá outras providências. Diário Oficial União. 16 fev. 2004.

3. Ministério da Saúde (BR). Portaria Interministerial n 1.802, de 26 de agosto de 2008. Institui o Programa de Educação pelo Trabalho para a Saúde - PET-Saúde. Diário Oficial União. 25 jun 2007.

4. Haddad AE, Brenelli SL, Cury GC, Puccini RF, Martins MA, Ferreira JR, et al. Pró-saúde e Pet-Saúde: a construção da política brasileira de reorientação da formação profissional em saúde. Editorial. Rev Bras Educ Med. 2012;36(1 supl 1):3-4. http://dx.doi.org/10.1590/ S0100-55022012000200001

5. Minsitério da Saúde (BR), Secretaria de Gestão do Trabalho e da Educação na Saúde. Edital no 24, de 15 de dezembro de 2011. [Seleção de projetos de Instituições de Educação Superior (IES) em conjunto com Secretarias Municipais e/ou Estaduais de Saúde para participação no Programa Nacional de Reorientação da Formação Profissional em Saúde (Pró-Saúde) articulado ao Programa de Educação pelo Trabalho para a Saúde - PET-Saúde]. Diário Oficial União. 16 dez. 2011;Seção 3:268.

6. Freitas MC. Os intelectuais e as representações da nação: um sertão chamado Brasil. Hist Cienc Saude-Manguinhos. 2001;8(3):774-7. http://dx.doi.org/10.1590/S010459702001000400017

7. Lima NT. Um sertão chamado Brasil. Rio de Janeiro: Revan; 2003. 
8. Nétto OBS, Moura SM, Lima MDM, Lages GP, Mendes RFO, Moura LFAD. O prósaúde no curso de odontologia da Universidade Federal do Piauí (UFPI): relato de uma vivência de cinco anos. Ciênc Cuid Saúde. 2013; 12(2):391-7. http://dx.doi.org/10.4025/ cienccuidsaude.v12i2.21746

9. Pedrosa JI, Leal VM, Carvalho ADF. O perfil da formação de profissionais na área de saúde na UFPI: um estudo sobre ensino na saúde: pesquisa de base construída em resposta ao Edital no 24/2010 - CAPES/DPB/CGPE/C II - Pro-ensino na Saúde. Teresina; 2011.

10. Gadelha JA. O intercessor tenda do conto. Entrevista concedida a Iza Sardenberg. Rede Humaniza SUS; 29 set 2013 [acesso 26 abr 2015]. Disponível em: http://www. redehumanizasus.net/66079-o-intercessor-tenda-do-conto

11. Freire P. Pedagogia da autonomia: saberes e práticas necessários à prática educativa. 27a ed. São Paulo: Paz e Terra; 1996. 
Trata-se do relato da experiência vivida pelos atores dos cenários do Programa de Educação pelo Trabalho para a Saúde (PET-Saúde) da Universidade Federal do Piauí (UFPI), Brasil, desenvolvido entre setembro de 2012 e agosto de 2014. Para os atores envolvidos - alunos, preceptores e tutores - a experiência nos cenários de atuação foi fundamental para a aquisição de novas relações, novos conhecimentos, e a produção de novas subjetividades. Nesse contexto, a aproximação com os serviços e com o cotidiano da população passa a ser elemento desconstrutor da cultura do "profissional neutro, individualista e competitivo", abrindo caminhos para a formação de profissionais comprometidos ética e socialmente. Assim, é possível inferir que o caminho oportunizado pela integração ensino-serviço-comunidade tem uma potência latente de transformação de saberes e fazeres, vivenciados em comunhão pelos diferentes atores envolvidos.

Palavras-chave: Sistema Único de Saúde. Educação em saúde. Serviços de integração docente-assistencial. Promoção da saúde.

\section{PET-Health: a potentially transforming experience in the undergraduate course}

This is a report on the experiences of the participants who performed scenarios in the Education by Work for Health Program (PET-Health) at the Federal University of Piaui (UFPI), Brazil, from September 2012 to August 2014. For the participants involvedstudents, preceptors, and mentors-the experience acquired in performing these scenarios was crucial in acquiring new relationships and knowledge and in producing new subjectivities. In this context, the combination of the services and the daily life of the population became the deconstructing element for the culture of the "neutral, individualistic, and competitive professional" and opened the door for the development of professionals who were socially and ethically committed. Thus, it may be possible to infer that the path created by the integration of the teaching-service-community has the latent potential to transform the knowledge and practices of the different participants.

Keywords: Brazilian Health System. Health education. Teaching care integration services. Health promotion.

\section{PET-Salud: una experiencia potencialmente transformadora en la educación de pregrado}

Se trata de un relato de la experiencia de los actores de los escenarios del Programa de Educación en el Trabajo para la Salud (PET-Salud), en la Universidad de Piauí (UFPI), Brasil, desarrollado desde septiembre 2012 hasta agosto 2014. Para los actores involucrados, estudiantes, preceptores y tutores, la experiencia en los escenarios de actuación fue fundamental para la adquisición de nuevas relaciones, nuevos conocimientos y la producción de nuevas subjetividades. En ese contexto, la aproximación con los servicios y el cotidiano de la población se convierte en elemento deconstructivo de la cultura del "profesional neutral, individualista y competitivo", abriendo el camino para la formación de profesionales ética y socialmente comprometidos. De este modo, es posible inferir que el camino oportunizado mediante la integración enseñanza-servicio-comunidad tiene una potencia latente de transformación de saberes y haceres, experimentados en la comunión de los diferentes actores involucrados.

Palabras clave: Sistema Brasileño de Salud. Educación en salud. Servicios de integración docente assistencial. Promoción de la salud. 
